\title{
Selective digestive decontamination, a seemingly effective regimen with individual benefit or a flawed concept with population harm?
}

James C. Hurley ${ }^{1,2^{*}}$ (1)

\begin{abstract}
Selective digestive decontamination (SDD) regimens, variously constituted with topical antibiotic prophylaxis (TAP) and protocolized parenteral antibiotic prophylaxis (PPAP), appear highly effective for preventing ICU-acquired infections but only within randomized concurrent control trials (RCCT's). Confusingly, SDD is also a concept which, if true, implies population benefit. The SDD concept can finally be reified in humans using the broad accumulated evidence base, including studies of TAP and PPAP that used non-concurrent controls (NCC), as a natural experiment. However, this test implicates overall population harm with higher event rates associated with SDD use within the ICU context.
\end{abstract}

Keywords: Bacteremia, Mechanical ventilation, Selective digestive decontamination, Polymyxin

\section{Introduction}

Selective digestive decontamination (SDD) is both a variously constituted antibiotic regimen and an unreified concept. SDD regimens appear highly effective for preventing ICU-acquired infections [1-4]. The SDD concept arose 50 years ago within experiments to improve supportive care for neutropenic patients. Like vaccination interventions, the SDD concept has infection prevention implications for both individual patients and populations [5-8].

SDD has multiple confusing aspects. The applications and composition of SDD regimens have drifted far from that originally conceived. It is neither a single regimen nor protocol. The mode of action, benefits and associated risks remain unclear despite extensive study among various ICU, haematology and other immunocompromised

\footnotetext{
*Correspondence: jamesh@bhs.org.au; hurleyjc@unimelb.edu.au ${ }^{1}$ Melbourne Medical School, University of Melbourne, Melbourne, Australia

Full list of author information is available at the end of the article
}

patient groups. The SDD studies used different study designs (Fig. 1), different end points and different target populations.

This breadth of study findings, within studies of regimens using one or both of the two main SDD components, 'TAP' and 'PPAP', provides a unique and valuable natural experiment with which to test the SDD concept and its implications to the 'whole of ICU' population.

Here, SDD is referred to by its two main components 'TAP' and 'PPAP', so as to minimize ambiguity between SDD regimens and the unreified SDD concept.

\section{SDD, the conceptual origin}

The SDD concept arose fifty years ago when neutropenia was the major limiting factor towards developing effective anti-leukemic chemotherapy. Pseudomonas and other Gram-negative (GN) bacteremias complicating chemotherapy-associated neutropenia were associated with high mortality. In this era, with few effective antipseudomonal antibiotics, preventing acquired infections

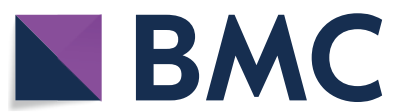

(c) The Author(s) 2021. Open Access This article is licensed under a Creative Commons Attribution 4.0 International License, which permits use, sharing, adaptation, distribution and reproduction in any medium or format, as long as you give appropriate credit to the original author(s) and the source, provide a link to the Creative Commons licence, and indicate if changes were made. The images or other third party material in this article are included in the article's Creative Commons licence, unless indicated otherwise in a credit line to the material. If material is not included in the article's Creative Commons licence and your intended use is not permitted by statutory regulation or exceeds the permitted use, you will need to obtain permission directly from the copyright holder. To view a copy of this licence, visit http://creativecommons.org/licenses/by/4.0/. The Creative Commons Public Domain Dedication waiver (http://creativeco mmons.org/publicdomain/zero/1.0/) applies to the data made available in this article, unless otherwise stated in a credit line to the data. 


\section{a}

\section{Randomized Concurrent Control trial (RCCT) Control vs SOD}

\section{b \\ Randomized Concurrent Control trial (RCCT) Control vs SDD}

C

\section{Duplex trial Control [PPAP] vs SDD

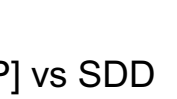

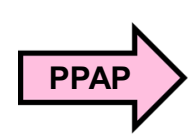

\section{d \\ d (NCC)}
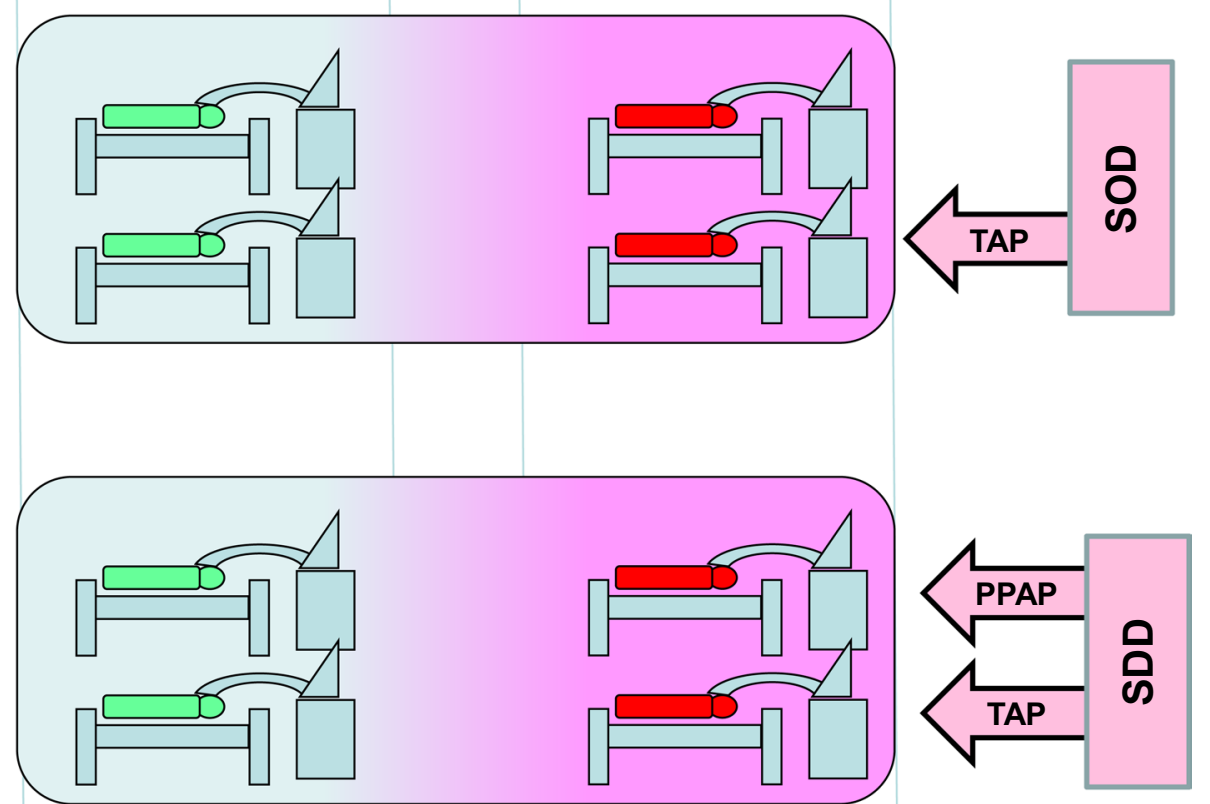

(n)
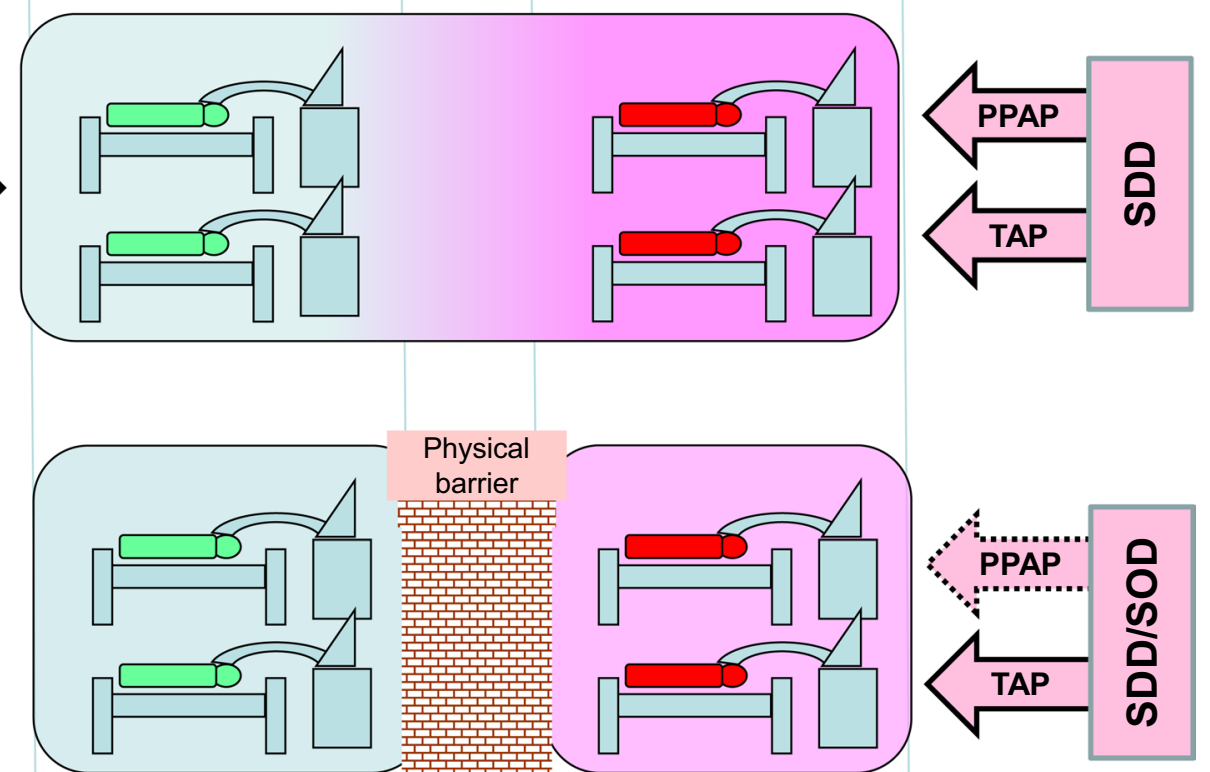

Fig. 1 Schematic of ICU patients as intervention (right) and control (left) groups receiving mechanical ventilation in an ICU. The intervention and control groups are either concurrent (a-c), or non-concurrent (d) and separated by a physical or temporal barrier. The intervention groups receive topical antibiotic prophylaxis (TAP) with (b, c, d) or without protocolized parenteral antibiotic prophylaxis (PPAP) (a, d). Duplex studies are those where control group patients received PPAP (RCCT-duplex studies; $\mathbf{c}$ ). The colour gradient indicates that the contextual effect emanating from intervention patients within the ICU that is implied by the SDD concept associated with the use of TAP 
among high-risk neutropenic patients required protective isolation $[8,9]$.

The SDD concept arose from studies using irradiated chimeric mice transplanted with leukemic cells which were at high risk of lethal blood stream infection arising from the digestive tract [5-7]. Earlier experiments demonstrated that increased susceptibility to oral challenge with Salmonella enteritidis was associated with loss of normally resident intestinal flora following prior antibiotic exposure. The novel observation within neutropenic mice was that this susceptibility varied depending on the timing and scale of the experimental antibiotic and irradiation exposures and that 'selective' antibiotic exposure prevented lethal bacteremia following radiation. These experimental mice were at high risk without protective isolation in germ-free conditions. A cross-infection incident with resistant Gram-negative bacteremia, arising from monkeys housed in the same research facility, dramatically illustrated this susceptibility with extensive loss of experimental mice [7].

Five surprising observations emerging from these seminal experiments underpin the SDD concept [5-8]. Firstly, exposure to orally administered antibiotics sparing the anaerobic flora enabled the mice to tolerate radiation doses two Gy higher versus mice not antibiotic exposed. Second, oral administration of single antibiotics, such as streptomycin, kanamycin or neomycin, resulted in better survival and lower incidences of bacteremia versus exposure to all three antibiotics in combination. Presumably, single antibiotic exposure caused 'selective effects' on the intestinal flora. Third, the risk associated with loss of colonization resistance was quantifiable as the oral bacterial dose required to establish intestinal tract colonization in $50 \%$ of mice following challenge with bacteria such as Klebsiella pneumoniae or Pseudomonas aeruginosa. For example, mice lacking colonization resistance sustained colonization levels that were $10^{5}$-fold higher and required lower challenge doses, being $10^{6}$-fold lower. The colonization resistance time course was characteristic, a nadir at four days with recovery at three weeks following antibiotic exposure. The recovery corresponded to the time taken to clear challenge bacteria from the intestinal tract. Finally, most surprisingly, on recovery, this colonization resistance was enhanced. Moreover, it was transferable as a contextual effect. That is, germ-free mice acquired colonization resistance from recovered mice housed in the same cage, or even simply being housed in cages contaminated by faecal flora from recovered mice [5].

With the SDD concept seemingly unverifiable in humans, as replicating the challenge studies undertaken in irradiated chimeric mice was not possible, translation of the concepts into clinical applications followed. As colonization resistance appeared most closely associated with anaerobic flora, a 'traffic light' classification of therapeutic antibiotics for at risk patients resulted. 'Red light' antibiotics, such as amoxicillin and clindamycin, with known activity against anaerobic flora, were to be avoided to minimize loss of colonization resistance [8].

The results of limited human volunteer colonization resistance experiments are difficult to summarize. It was highly variable between human volunteers and difficult to quantify. Notably, some findings in humans differed to those in experimental mice. The traffic light classification of antibiotics was abandoned and two 'amber light' antibiotics, trimethoprim-sulfamethoxazole and cefotaxime, each having potential anti-anaerobic activity at higher doses, were later adopted as key components of SDD regimens used among haematological and mechanically ventilated ICU patients, respectively $[8,10]$.

\section{SDD regimen change}

Ideally, the properties of enteral (TAP) antibiotics would include activity against Pseudomonas, being non-absorbable (to maximize activity within the bowel lumen), well tolerated and cheap. As no one antibiotic agent satisfied all criteria, more than 20 TAP regimens with various combinations of two or three enteral antibiotics, such as polymyxin, tobramycin, gentamicin, netilmicin or nalidixic acid, were empirically derived.

Confusingly, other 'SDD' regimens developed to prevent bacteremia in neutropenic patients included agents systemically adsorbed after oral administration, such as trimethoprim-sulfamethoxazole, ciprofloxacin, norfloxacin, ofloxacin or cefuroxime. Whether these 'SDD' regimens mediated the prevention effect via intestinal decontamination versus systemic effects following adsorption is unclear.

Usually, SDD regimens include an anti-fungal agent to minimize yeast overgrowth. Surprisingly, among 33 RCCT's among critically ill patients, SDD regimens outperformed single-agent anti-fungal prophylaxis with respect to reducing yeast colonization, invasive yeast infection and in-hospital mortality [11].

The duration and frequency of SDD regimen applications generally corresponds to time at risk being the duration of either neutropenia or mechanical ventilation. Regimens developed for ICU patients additionally include PPAP, such as such as cefotaxime, ceftriaxone and ceftazidime, for the first four days. Whether PPAP provides 'pre-emptive therapy' for infections potentially incubating on admission or provide interim coverage while the TAP components decontaminate the entire intestinal tract, is unclear. The exclusion from analysis of patients within SDD trials who are either extubated or died within the initial four days potentially creates immortal time bias. 
Confusingly, regimens without PPAP, such as TAP applications to the oropharynx, being selective oropharyngeal decontamination (SOD), developed specifically for pneumonia prevention, unexpectedly also prevented bacteremia [10]. Also, within some RCCT's, concurrent control group patients received PPAP (duplex studies, [Fig. 1c]) to mitigate cross-infection risks. Of note, the summary VAP and mortality prevention effects derived from duplex RCCT's are not significant [1].

Trauma patients, whose colonization resistance is likely intact on admission to ICU, are considered ideal for SDD [12]. While early analyses indicated better mortality outcomes for surgical or trauma versus medical patient subgroups, more recent analyses showed similar apparent benefits among ICU patient subgroups [2, 13, 14].

\section{SDD a triple misnomer}

Given the above, it is unclear whether SDD regimens mediate effects through selective removal (decontamination) of pathogens from the gut colonizing flora, whether the optimal location of decontamination is the gut or elsewhere, what the respective roles of TAP versus PPAP are towards the mediation of SDD effect, and whether complete decontamination is required. Some have studied whether polymyxin prevents adsorption of endotoxin from the bowel lumen as being an explanation for SDD effectiveness among ICU patients. In light of these uncertainties, the term 'SDD' is a triple misnomer and 'control of gut overgrowth (COGO)' better describes the presumed mediation $[15,16]$.

\section{SDD in neutropenia}

In the 1970s, it was hoped that SDD regimens (nearly always TAP) used post-chemotherapy would enable neutropenic patient care without protective isolation $[8,9,17,18]$. Clinical trials comparing protective isolation versus TAP used separately and together in neutropenic patients are confusing and their relative merits were unclear [17]. While the combination appeared to be beneficial, the studies were heterogeneous, were often small ( $<50$ patients per group), random allocation depended on the isolation unit availability at the time of random assignment, and protective isolation was difficult to standardize and moreover, psychologically distressing. Also, the SDD regimens varied and were poorly tolerated. For example, the taste of TAP using oral gentamicin, nystatin and vancomycin (GVN) was described as 'dreadful'. Of great concern, the premature discontinuation of GVN resulted in rebound recolonization by Pseudomonas and Candida species in the gut causing bacteremia and other infections $[9,17]$.

Despite numerous SDD studies among haematological patients, many questions, such as optimal component antibiotics, optimal end points, mechanism of action and population effects, remained unanswered. The results of SDD studies among haematological and other patient groups failed to demonstrate the apparent success that later emerged from SDD studies among ICU patients receiving mechanical ventilation [1].

After 1980, interest in SDD use among neutropenic patients waned for three reasons. Effective anti-pseudomonal coverage for febrile neutropenia episodes became available. Well-tolerated single-agent prophylaxis regimens, using either trimethoprim-sulfamethoxazole or the newly available quinolone agents, had been demonstrated to reduce morbidity and numbers of Gram-negative infections in neutropenic patients. Rebound among high-risk patients after premature TAP withdrawal lingered as a safety concern. Recent European guidelines and commentaries on neutropenia infection prevention do not mention SDD regimens [18].

\section{Pivot to ICU patients}

Patients receiving more than $48 \mathrm{~h}$ of mechanical ventilation frequently develop ventilator-associated pneumonia (VAP) with Pseudomonas, and other GN bacteria, acquired during hospitalization. VAP and other acquired infections increase mortality and are difficult to treat.

The summary evidence from sixteen early RCCT's (3361 ICU patients) implied that only five and 23 patients would need to be treated with SDD to prevent one infection and one death, respectively [19]. This evidence, recently updated with results from 41 RCCT's $(11,004$ ICU patients) [1], enables TAP to be compared versus five other VAP prevention interventions (Table 1) [20-23] using summary data as tabulated within recent Cochrane reviews. TAP appears highly effective towards preventing VAP versus these other interventions and, as TAP combined with PPAP, appears to be the only intervention effective at reducing mortality.

Comparing the counts of VAP with various specific bacteria isolated (Fig. 2) reinforces the impression that, in contrast to five other interventions, in two broad categories drawn from the evidence base (Table 1), SDD has profound and selective anti-pseudomonal effects [24-28].

However, several puzzling observations emerge from this literature reappraisal. Surprisingly, the median VAP and mortality incidences among the TAP intervention groups are similar to (i.e. not lower than) the other intervention group medians (Table 1, Fig. 3).

Likewise, the median Pseudomonas VAP incidence is similar versus the two broad intervention categories (Fig. 2a) and versus benchmark incidences derived either from the literature or global surveys [28]. Curiously, for VAP where either Staphylococcus, Acinetobacter 
Table 1 Summary of findings from Cochrane reviews of VAP prevention interventions ${ }^{a}$

\begin{tabular}{|c|c|c|c|c|c|c|c|c|c|}
\hline \multirow[t]{2}{*}{ Intervention } & \multirow[t]{2}{*}{ Ref } & \multicolumn{4}{|c|}{ VAP incidence (per 1000 patients) } & \multicolumn{4}{|c|}{ Mortality incidence (per 1000 patients) } \\
\hline & & Control & Intervention & RR; (95\% Cl) & $\mathrm{n} / \mathrm{N}$ & Control & Intervention & RR; (95\% Cl) & $\mathrm{n} / \mathrm{N}$ \\
\hline Semi-recumbent ${ }^{b}$ & {$[20]$} & 316 & 139 & $0.44 ; 0.11-1.77$ & $3 / 419$ & 276 & 240 & $0.87 ; 0.59-1.27$ & $2 / 307$ \\
\hline $\mathrm{HME}^{\mathrm{c}}$ & {$[21]$} & 167 & 155 & $0.93 ; 0.73-1.19$ & $13 / 2251$ & 247 & 257 & $1.03 ; 0.89-1 \cdot 2$ & $12 / 1951$ \\
\hline Probiotic $^{d}$ & {$[22]$} & 309 & 238 & $0.7 ; 0.52-0.95$ & $8 / 1018$ & 214 & 186 & $0.84 ; 0.58-1.22$ & $5 / 703$ \\
\hline Chlorhexidine $^{e}$ & {$[23]$} & 243 & 180 & $0.75 ; 0.62-0.91$ & $18 / 2451$ & 222 & 242 & $1.09 ; 0.96-1.23$ & $14 / 2014$ \\
\hline Tooth brushing $^{f}$ & {$[23]$} & 253 & 206 & $0.69 ; 0.44-1.09$ & $5 / 889$ & 269 & 237 & $0.87 ; 0.7-1.09$ & $5 / 889$ \\
\hline $\mathrm{TAP}+\mathrm{PPAP}^{g}$ & {$[1]$} & 417 & 179 & $0.43 ; 0.35-0.53$ & $17 / 2951$ & 303 & 255 & $0.84 ; 0.73-0.96$ & $18 / 5290$ \\
\hline TAP (alone) ${ }^{\mathrm{h}}$ & {$[1]$} & 324 & 162 & $0.50 ; 0.36-0.69$ & $13 / 1848$ & 305 & 296 & $0.97 ; 0.87-1.07$ & $15 / 3274$ \\
\hline TAP + PPAP (versus PPAP) ${ }^{i, j}$ & {$[1]$} & 303 & 278 & $0.82 ; 0.58-1.16$ & $6 / 247$ & 237 & 221 & $0.92 ; 0.72-1.18$ & $7 / 1039$ \\
\hline
\end{tabular}

${ }^{a} \mathrm{n} / \mathrm{N}$ is number of participants/number of studies

${ }^{\mathrm{b}}$ Semi-recumbent position; pneumonia is microbiologically confirmed VAP at $>48 \mathrm{~h}$ and mortality is ICU mortality at $>48 \mathrm{~h}$

' HME (heat and moisture exchanger); pneumonia measured at a median 4 days (from Analysis 1.3 on page 65 of ref [21]) and mortality measured at a median 8 days

d Probiotic; pneumonia is VAP measured at a median 37 days and mortality measured at a median 35 days

${ }^{e}$ Chlorhexidine (mouth rinse or gel); pneumonia is VAP measured at a median 1 month and mortality measured at a median 1 month

${ }^{f}$ Toothbrushing; pneumonia is VAP measured at a mean 1 month and mortality measured at a mean 1 month

${ }^{9}$ TAP + PPAP studies; pneumonia is respiratory tract infection at unspecified follow up and mortality is at unspecified follow up. These studies resemble those having designs as in Fig. $1 \mathrm{~b}$

${ }^{\mathrm{h}}$ TAP alone; pneumonia is respiratory tract infection at unspecified follow up (note this does not include 6 studies for which the control group received PPAP) and mortality is at unspecified follow up. These studies resemble those having designs as in Fig. 1a

'TAP + PPAP versus PPAP (duplex studies); pneumonia is respiratory tract infection at unspecified follow up and mortality is at unspecified follow up. These studies resemble those having designs as in Fig. 1c

j Note that only one study [10] having a NCC design (as in Fig. 1d) is included within the systematic review of TAP[1]

or Candida have been isolated, the majority of control groups of TAP studies and at least half of TAP intervention groups have incidences above the respective benchmarks (Fig. 2) [24-28].

Comparing RCCT group incidences, unadjusted for underlying patient risk, from disparate studies, unweighted for study size or quality (Table 1 and the boxplots as in Fig. 2 \& 3), could be criticized. Such comparisons of group level incidences across studies of diverse design, patient mix and origin are ecological, simplistic and poorly reflect patient level TAP effects. Such comparisons, using group level incidences in the estimation of causal effects of interventions for individual patients, are widely discredited. Also, VAP diagnosis is potentially subjective, and its microbiological documentation potentially masked by TAP and anti-septic interventions.

While simplistic, these broad comparisons across the evidence base enable an appraisal of TAP population effects within the 'whole of ICU. Of note, in contrast to estimating individual patient level effects of interventions, determining the population effect of any intervention is not possible within any one RCCT or even within several RCCT's of a single intervention.

That TAP effects would extend beyond individual recipients, mediated by cross-infection, as had been noted in the original colonization resistance experiments in mice, created an expectation of benefit to concurrent non-recipients within RCCT's of TAP [12]. Cross-infection, whether aerobic flora from control group to intervention group patients or, anaerobic flora from intervention group to control group patients, within conventional RCCT's would undermine estimates of TAP efficacy. Cross-infection of either type, being inapparent within even moderate sized RCCT's [29], would bias RCCT results towards the null [12]. This expectation, based on testable postulates [24], prompted further evaluation within studies using NCC rather than RCCT design.

\section{Pivot to ICU non-concurrent controlled trials}

NCC studies mitigate these cross-infection threats by segregating enrolled patients, either into separate ICU's or, non-concurrent periods in the same ICU. The NCC design (Fig. 1d), where the unit of randomization is the ICU, not the patient, also has logistical benefits. However, substantially more patients are required to adequately power CRT's due to the non-independence of observations within each ICU [30]. Also, blinding within NCC design studies is difficult and bacteremia, being less subjective than VAP, is the preferred end point.

Despite expectations, the results of three large [each $>5000$ patients and $>13$ ICU's] CRT's were marginal compared to RCCT's results (Table 1) [10, 13, 31]. A fourth is in progress. One found similar overall mortality 


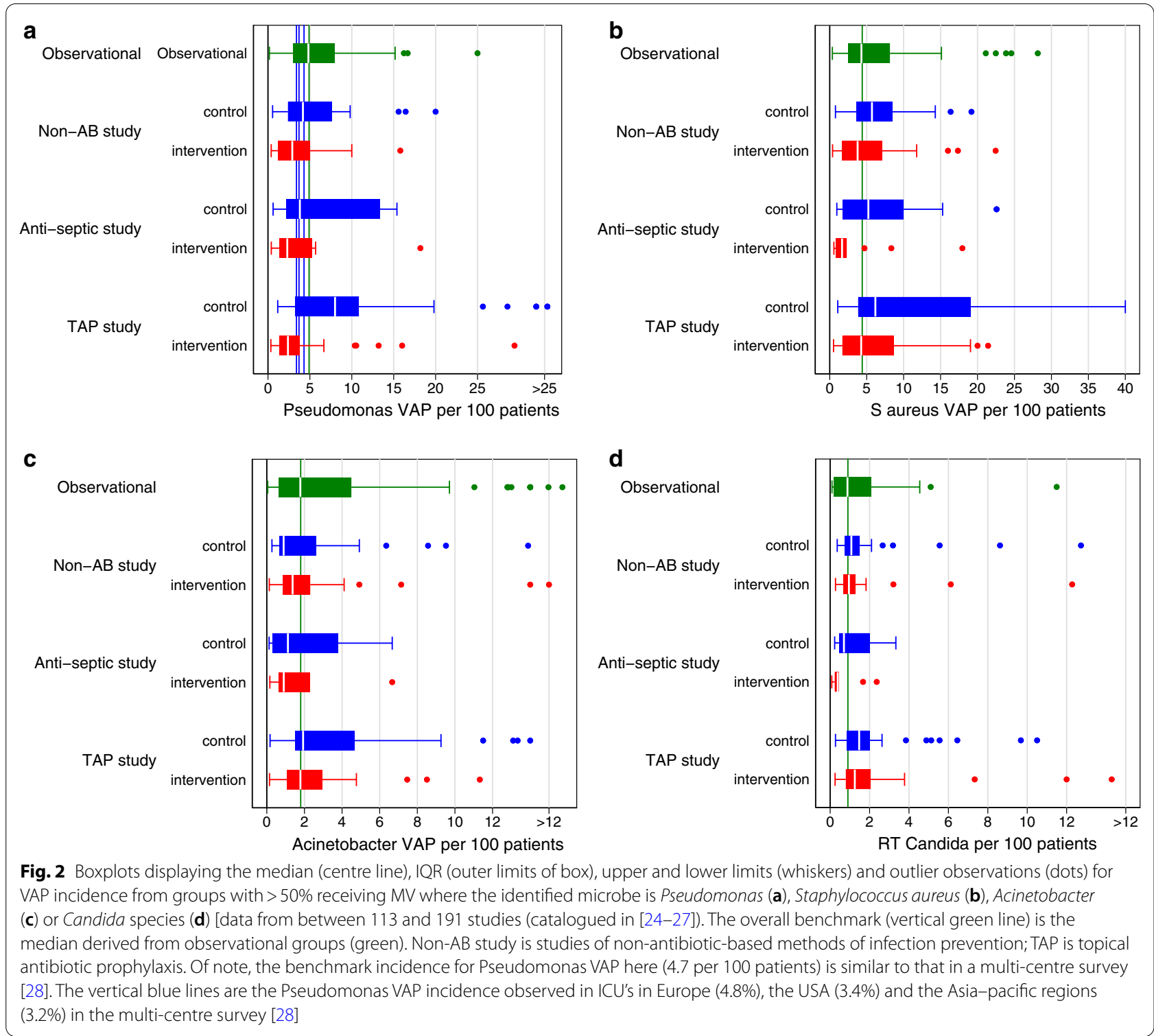

within ICU's randomized to SOD, SDD or standard care with significant differences emerging after adjusting for differences in underlying patient mortality risk [10]. The second found lower day- 28 mortality and ICU-acquired bacteremia associated with SDD versus SOD but lacked standard care control groups [13]. The third, and largest, found no reduction, with either SDD or SOD, in either bacteremia or mortality even in adjusted analyses [31].

Of concern, the statistical adjustment underlying the significant results obtained in the first CRT [10], and in subsequent individual patient data meta-analyses [2], fails to account for any carry-over of contextual 'wholeof-ICU' effects between TAP and control periods.
Moreover, most surprisingly, the median incidence for VAP, bacteremia and ICU mortality among NCC control groups are each closer to literature benchmarks versus RCCT control groups (Fig. 3) [24-28]. These paradoxical observations, arising also in comparisons of blood stream infections, whether overall or for specific types, and ICU mortality end points, are each unexplained in regression models and invite a reappraisal of other 'whole of ICU' consequences of TAP exposure [32-37].

\section{Rebound}

Patient outcomes following SDD cessation and following ICU discharge are an area of increasing research. Hospital-acquired infections are up to $50 \%$ more 


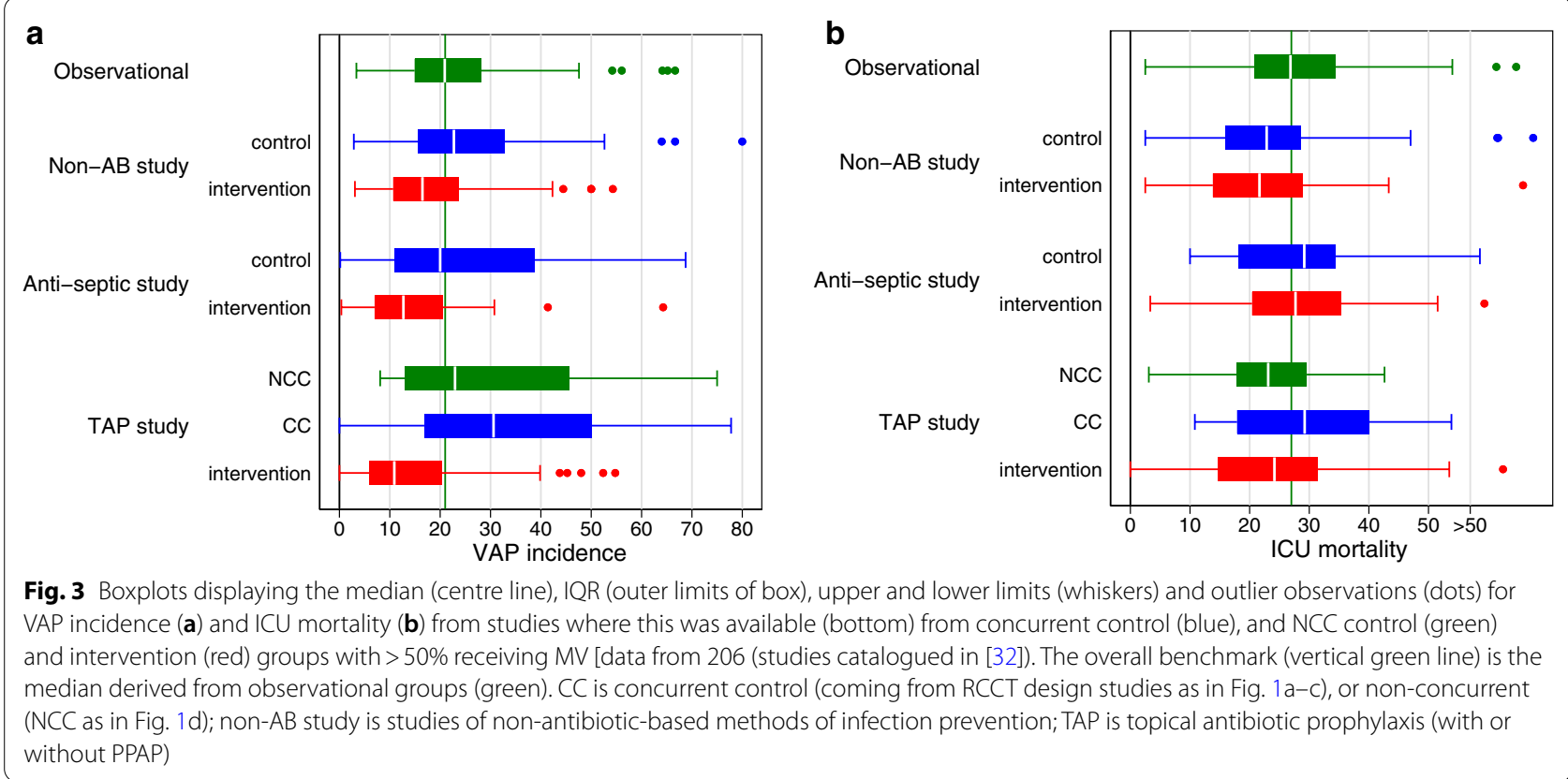

common among patients discharged after receiving either SDD or SOD during ICU stay versus patients discharged following standard care [38].

Rebound follows cessation of TAP [39-45]. Rebound following premature cessation of TAP in haematology patients was a major concern [9]. P. aeruginosa rebound among ICU patients occurred following both continuous TAP use [41] and aerosolized polymyxin use as prevention during alternate months [42]. The optimal time for washout after SDD/SOD withdrawal to avoid rebound carrying-over into subsequent CRT control periods is unclear.

Resistant GN microorganisms, colonizing respiratory and rectal sites, rebound following periods of TAP use to levels higher than in baseline periods. This rebound occurs among the 'whole of ICU' population [39]. Whether antibiotic-sensitive bacteria likewise rebound is unclear and difficult to study except in mice. Patients receiving TAP can serve as reservoirs for Pseudomonas strains appearing among control group infections [40]. Whether rebound occurs within the intestinal 'resistome', which includes non-culturable flora, and the broader question of consequences for antibiotic resistance and even for bacteria which exhibit antibiotic dependency, are areas of active investigation [46, 47]. Likewise, Candida interacting with bacteria within the microbiome might promote invasive bacterial infection from higher Candida colonization resulting from TAP [49].

\section{Herd effects of SDD}

Herd effects, of great consequence to non-recipient individuals concurrent within populations exposed to vaccine interventions, cannot be estimated within single populations examined in isolation. These estimates require thousands of participants within multiple exposed and unexposed neighbourhoods to achieve adequate study power. For example, a CRT demonstrating typhoid vaccination herd effects enrolled 60,000 residents across 40 contiguous Eastern Kolkata neighbourhoods [50].

Estimating TAP herd effects, a crucial 'whole of ICU' question, would face multiple challenges. Three small studies (each $<200$ patients and $<3$ ICU's) were inconclusive. The two largest ( $>5000$ patients and 13-16 ICU's $[10,31])$ CRT's of TAP completed to date were underpowered to detect any direct TAP effect on any mortality end point in unadjusted analyses. Additionally, TAP herd effects would be diffused across multiple microbial end points, unlike typhoid vaccination studies wherein typhoid fever is the only relevant end point.

Finally, the greatest challenge in studying TAP herd effects is the participation of non-recipient patients. In consenting them for participation, is there equipoise regarding whether non-recipients indirectly derive benefit versus harm from being concurrent to TAP recipients in the ICU? What evidence underlies this equipoise? For vaccine interventions, herd protection with benefit to non-recipients appears plausible from the accumulated history of immunity resulting from outbreaks and 


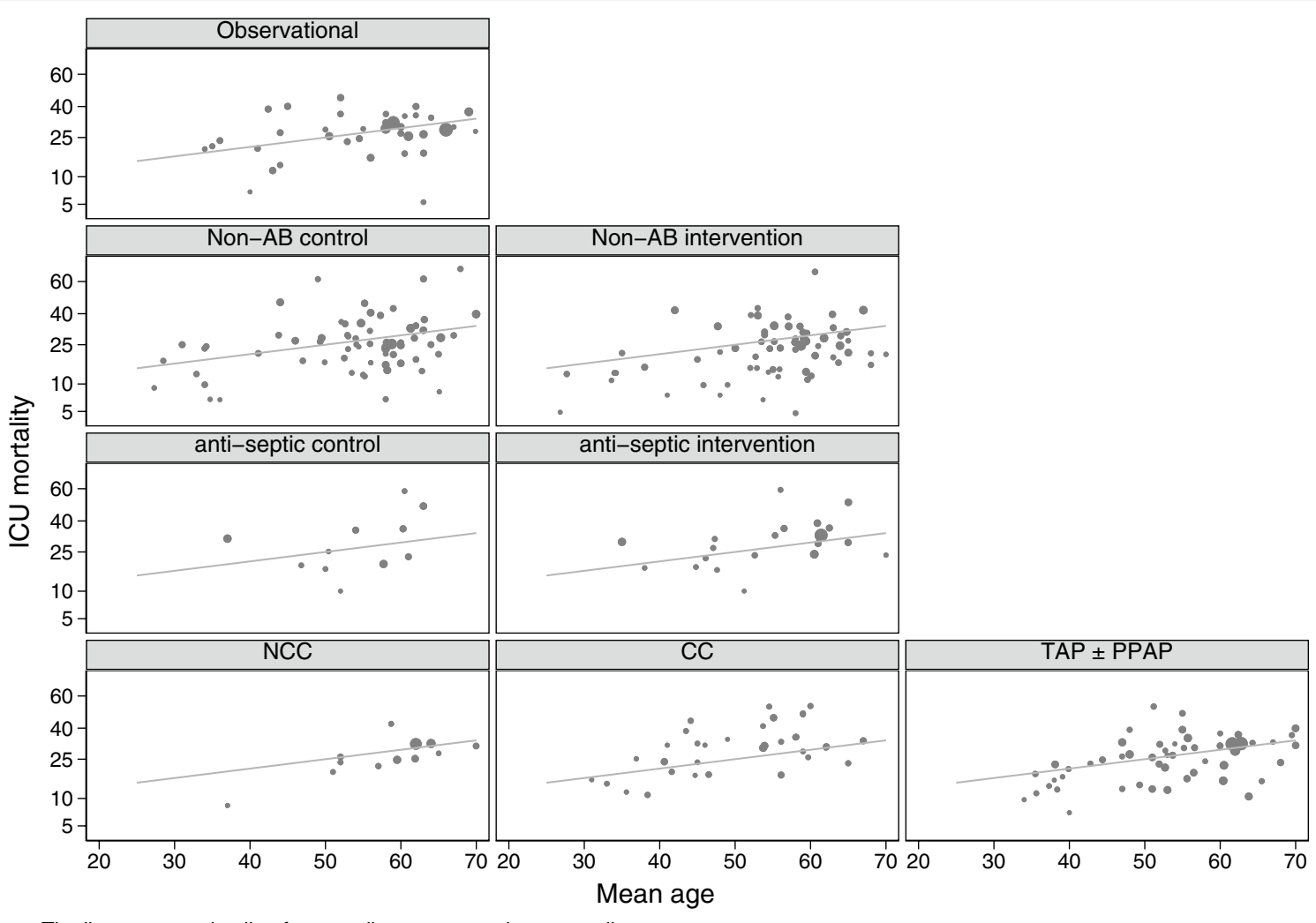

The linear regression line for mortality versus age is across all groups

Fig. 4 ICU mortality incidence among 175 groups from studies of observational (top row), and control (left most and middle panels) and intervention (right most panels) groups of non-antibiotic (second row), topical anti-septic (third row) and topical antibiotic (bottom row) studies of VAP prevention versus group mean age. Also shown for reference is the linear regression line of ICU mortality incidence versus group mean age as derived across all groups. The figure is adapted from reference [32] and used here under the terms of the Creative Commons Attribution 4.0 International License (http://creativecommons.org/licenses/by/4.0/)

vaccine interventions. What of the accumulated history with TAP use within ICU's?

More simply, 'flipping' the entire evidence base of VAP prevention interventions to simulate a multi-centre CRT of TAP use among ICU's enables a reappraisal of the 'whole of ICU' effects of TAP. This 'natural experiment' [32-37] identifies control groups that are either exposed versus not exposed to concurrent patients receiving TAP within the ICU. The higher incidences of ICU mortality [32], which remains evident within a regression adjusted for group mean age (Fig. 4), and several infections among exposed non-recipients (i.e. concurrent control group patients within TAP RCCT's) versus those not exposed (Fig. 3) are unexplained. On the other hand, the similarity of the incidence of these various end points among TAP intervention groups with benchmarks and with the incidences among all other intervention and control groups of various types, with the notable exception of RCCT control groups (Table 1), raises doubt about the population safety of TAP.

\section{Conclusion}

Strangely, despite high apparent efficacy of SDD regimens, within ICU based RCCT's, the concurrent control group incidences of several infections and mortality are higher versus other groups including groups within NCC studies of SDD regimens. These results are contrary to the original SDD concept. Surprisingly, the incidences within the TAP intervention groups are closer to literature-derived benchmarks. While these discrepancies remain unexplained, SDD regimens appear unsafe for use in the ICU.

\section{Abbreviations}

COGO: Control of gut overgrowth; GN: Gram-negative; ICU: Intensive care unit; MV: Mechanical ventilation; PPAP: Protocolized parenteral antibiotic prophylaxis; NCC: Non-concurrent control; CC: Concurrent control; RCCT: Randomized concurrent control trial; SOD/SDD: Selective digestive decontamination/selective digestive decontamination; TAP: Topical antibiotic prophylaxis.

\section{Authors' contributions}

As sole author, JH produced the design of the study, performed the statistical analysis and wrote the manuscript. JH read and approved the final manuscript 
and is the guarantor of the paper. The author read and approved the final manuscript.

\section{Funding}

This research has been supported by the Australian Government Department of Health and Ageing through the Rural Clinical Training and Support (RCTS) program.

\section{Availability of data and materials}

Supportive data are available in the author's cited publications [16, 24-27, 29, $32-37,49]$.

\section{Declarations}

\section{Ethics approval and consent to participate}

Being an analysis of published work, ethics committee review of this study was not required.

\section{Consent for publication}

Not applicable.

\section{Competing interests}

The author declares that they have no competing interests.

\section{Author details}

${ }^{1}$ Melbourne Medical School, University of Melbourne, Melbourne, Australia. ${ }^{2}$ Division of Internal Medicine, Ballarat Health Services, PO Box 577, Ballarat, VIC 3353, Australia.

Received: 30 June 2021 Accepted: 24 August 2021

Published online: 01 September 2021

\section{References}

1. Minozzi S, Pifferi S, Brazzi L, Pecoraro V, Montrucchio G, D’Amico R. Topical antibiotic prophylaxis to reduce respiratory tract infections and mortality in adults receiving mechanical ventilation. Cochrane Database Syst Rev. 2021. https://doi.org/10.1002/14651858.CD000022.pub4.

2. Plantinga NL, de Smet AM, Oostdijk EA, et al. Selective digestive and oropharyngeal decontamination in medical and surgical ICU patients: individual patient data meta-analysis. Clin Microbiol Infect. 2018;24(5):505-13.

3. Silvestri L, van Saene HK, Weir I, Gullo A. Survival benefit of the full selective digestive decontamination regimen. J Crit care. 2009;24(3):474-e7.

4. Hurley JC. Prophylaxis with enteral antibiotics in ventilated patients: Selective decontamination or selective cross-infection? Antimicrob Agents Chemother. 1995;39:941-7.

5. Van der Waaij D, Berghuis-de Vries JM, Lekkerkerk-Van der Wees JE. Colonization resistance of the digestive tract in conventional and antibiotictreated mice. J Hygeine. 1971;69(3):405-11.

6. Vollaard EJ, Clasener HA. Colonization resistance. Antimicrob Agents Chemother. 1994;38(3):409.

7. Van der Waaij D. History of recognition and measurement of colonization resistance of the digestive tract as an introduction to selective gastrointestinal decontamination. Epidemiol Infect. 1992;109(3):315.

8. Clasener HA, Vollaard EJ, van Saene HKF. Selective decontamination and long-term systemic prophylaxis in leukopenic or intensive-care patients. Rev Infect Dis. 1987;9:295-328.

9. Schimpff SC, Greene WH, Young VM, Fortner CL, Cusack N, Block JB, Wiernik PH. Infection prevention in acute nonlymphocytic leukemia. Laminar air flow room reverse isolation with oral, nonabsorbable antibiotic prophylaxis. Ann Intern Med. 1975;82(3):351-8.

10. De Smet AM, Kluytmans JA, Cooper BS, et al. Decontamination of the digestive tract and oropharynx in ICU patients. N Engl J Med. 2009;360:20-31

11. van Till JO, van Ruler O, Lamme B, et al. Single-drug therapy or selective decontamination of the digestive tract as antifungal prophylaxis in critically ill patients: a systematic review. Crit Care. 2007;11:R126.
12. Stoutenbeek CP, Van Saene HK, Miranda DR, et al. The effect of selective decontamination of the digestive tract on colonisation and infection rate in multiple trauma patients. Intensive Care Med. 1984;10:185-92.

13. Oostdijk EA, Kesecioglu J, Schultz MJ, Visser CE, De Jonge E, van Essen EH, Bernards AT, Purmer I, Brimicombe R, Bergmans D, van Tiel F. Notice of retraction and replacement: Oostdijk et al. effects of decontamination of the oropharynx and intestinal tract on antibiotic resistance in ICUs: a randomized clinical trial. JAMA. 2014;312(14):1429-37.

14. Melsen WG, De Smet AM, Kluytmans JA, Bonten MJ. Selective decontamination of the oral and digestive tract in surgical versus non-surgical patients in intensive care in a cluster-randomized trial. Brit J Surg. 2012;99(2):232-7.

15. Silvestri L, Miguel A, van Saene HK. Selective decontamination of the digestive tract: the mechanism of action is control of gut overgrowth Intensive Care Med. 2012;38(11):1738-50.

16. Hurley JC. Structural equation modeling the "control of gut overgrowth" in the prevention of ICU-acquired Gram-negative infection. Crit Care. 2020;24(1):1-2

17. Donnelly JP. Selective decontamination of the digestive tract and its role in antimicrobial prophylaxis. J Antimicrob Chemother. 1993;31(6):813-29.

18. Pizzo PA. Management of patients with fever and neutropenia through the arc of time: a narrative review. Ann Intern Med. 2019:170(6):389-97.

19. D’Amico R, Pifferi S, Leonetti C, Torri V, Tinazzi A, Liberati A. Effectiveness of antibiotic prophylaxis in critically ill adult patients: systematic review of randomised controlled trials. BMJ. 1998;316(7140):1275-85.

20. Wang L, Li X, Yang Z, Tang X, Yuan Q, Deng L, Sun X. Semi-recumbent position versus supine position for the prevention of ventilator-associated pneumonia in adults requiring mechanical ventilation. Cochrane Database Syst Rev. 2016. https://doi.org/10.1002/14651858.CD009946. pub2.

21. Gillies D, Todd DA, Foster JP, Batuwitage BT. Heat and moisture exchangers versus heated humidifiers for mechanically ventilated adults and children. Cochrane Database Syst Rev. 2017. https://doi.org/10.1002/ 14651858.CD004711.pub3.

22. Bo L, Li J, Tao T, Bai Y, Ye X, Hotchkiss RS, Kollef MH, Crooks NH, Deng X Probiotics for preventing ventilator-associated pneumonia. Cochrane Database Syst Rev. 2014. https://doi.org/10.1002/14651858.CD009066. pub2.

23. Zhao T, Wu X, Zhang Q, Li C, Worthington HV, Hua F. Oral hygiene care for critically ill patients to prevent ventilator-associated pneumonia. Cochrane Database Syst Rev. 2020. https://doi.org/10.1002/14651858. CD008367.pub4.

24. Hurley JC. Incidences of Pseudomonas associated Ventilator-associated pneumonia within studies of respiratory tract applications of polymyxin: testing the Stoutenbeek concurrency postulates. Antimicrob Agents Chemother. 2018:62(8):e00291-18.

25. Hurley JC. Paradoxical Acinetobacter associated Ventilator associated pneumonia incidences within prevention studies using respiratory tract applications of topical polymyxin: benchmarking the evidence base. J Hosp Infect. 2018;100:105-13.

26. Hurley JC. Impact of selective digestive decontamination on respiratory tract Candida among patients with suspected ventilatorassociated pneumonia. A meta-analysis. Eur J Clin Microbiol Infect Dis. 2016;35:1121-35

27. Hurley JC. The perfidious effect of topical placebo: calibration of Staphylococcus aureus ventilator-associated pneumonia incidence within selective digestive decontamination studies versus the broader evidence base. Antimicrob Agents Chemother. 2013;57(9):4524-31.

28. Kollef MH, Chastre J, Fagon JY, François B, Niederman MS, Rello J, Torres A, Vincent JL, Wunderink RG, Go KW, Rehm C. Global prospective epidemiologic and surveillance study of ventilator-associated pneumonia due to Pseudomonas aeruginosa. Crit Care Med. 2014;42(10):2178-87.

29. Hurley JC. Inapparent outbreaks of ventilator-associated pneumonia: An ecological analysis of prevention and cohort studies. Infect Control Hosp Epidemiol. 2005;26:374-90.

30. Hurley JC. How the cluster randomized trial "works." Clin Infect Dis. 2020;70:341-6.

31. Wittekamp BH, Plantinga NL, Cooper BS, et al. Decontamination strategies and bloodstream infections with antibiotic-resistant microorganisms in ventilated patients: a randomized clinical trial. JAMA. 2018:320:2087-98. 
32. Hurley JC. Discrepancies in control groups mortality rates within studies assessing topical antibiotic strategies to prevent Ventilator-associated Pneumonia. An umbrella review. Crit Care Expl. 2020;2(1):e0076.

33. Hurley JC. Topical antibiotics as a major contextual hazard toward bacteremia within selective digestive decontamination studies: a metaanalysis. BMC Infect Dis. 2014;14:1

34. Hurley JC. ICU-acquired candidemia within selective digestive decontamination studies: a meta-analysis. Intensive Care Med. 2015;41:1877-85.

35. Hurley JC. Unusually high incidences of Pseudomonas bacteremias within topical polymyxin based decolonization studies of mechanically ventilated patients: benchmarking the literature. Open Forum Infect Dis. 2018;5(11):ofy256.

36. Hurley JC. Studies of selective digestive decontamination as a natural experiment to evaluate topical antibiotic prophylaxis and cephalosporin use as population-level risk factors for enterococcal bacteraemia among ICU patients. J Antimicrob Chemother. 2019;74(10):3087-94.

37. Hurley JC. Incidence of coagulase-negative staphylococcal bacteremia among ICU patients: decontamination studies as a natural experiment. Eur J Clin Microbiol \& Infect Dis. 2020;39(4):657-64.

38. de Smet AM, Hopmans TE, Minderhoud AL, Blok HE, Gossink-Franssen A, Bernards AT, Bonten MJ. Decontamination of the digestive tract and oropharynx: hospital acquired infections after discharge from the intensive care unit. Intensive Care Med. 2009;35(9):1609-13.

39. Oostdijk EA, de Smet AM, Blok HE, et al. Ecological effects of selective decontamination on resistant gram-negative bacterial colonization. Am J Resp Crit Care Med. 2010;181:452-7.

40. Tetteroo GWM, Wagenvoort JHT, Bruining HA. Bacteriology of selective decontamination: efficacy and rebound colonization. J Antimicrob Chemother. 1994;34:139-48.

41. Nardi G, Valentinis U, Proietti A, De Monte A, Di Silvestre A, Muzzi R, Peressutti R, Troncon MG, Giordano F. Epidemiological impact of prolonged systematic use of topical SDD on bacterial colonization of the tracheobronchial tree and antibiotic resistance. Intensive Care Med. 1993;19(5):273-8.
42. Feeley TW, Du Moulin GC, Hedley-Whyte J, et al. Aerosol polymyxin and pneumonia in seriously ill patients. New Engl J Med. 1975;293:471-5.

43. Klick JM, Du Moulin GC, Hedley-Whyte J, et al. Prevention of gram-negative bacillary pneumonia using polymyxin aerosol as prophylaxis. II. Effect on the incidence of pneumonia in seriously ill patients. J Clin Invest. 1975;55:514-9.

44. Armstrong PJ, Barr JG, Webb CH, et al. Epidemiology of Pseudomonas aeruginosa in an intensive care unit using selective decontamination of the digestive tract. J Hosp Infect. 1992;20:199-208.

45. De Jonge E, De Wilde RB, Juffermans NP, Oostdijk EA, Bernards AT, Van Essen EH, Kuijper EJ, Visser CE, Kesecioglu J, Bonten MJ. Carriage of antibiotic-resistant Gram-negative bacteria after discontinuation of selective decontamination of the digestive tract (SDD) or selective oropharyngeal decontamination (SOD). Crit Care. 2018;22(1):1.

46. Buelow E, Gonzalez TB, Versluis D, Oostdijk EA, Ogilvie LA, van Mourik MS, Oosterink E, van Passel MW, Smidt H, D'Andrea MM, de Been M. Effects of selective digestive decontamination (SDD) on the gut resistome. J Antimicrob Chemother. 2014;69(8):2215-23.

47. Hatcher J, Myers A, Donaldson H, Gordon AC, Meacher R, Baruah J. Comment on: effects of selective digestive decontamination (SDD) on the gut resistome. J Antimicrob Chemother. 2014;69:3444-5.

48. Zhu Y, Lu J, Han ML, Jiang X, Azad MA, Patil NA, Lin YW, Zhao J, Hu Y, Yu $\mathrm{HH}$, Chen K. Polymyxins bind to the cell surface of unculturable Acinetobacter baumannii and cause unique dependent resistance. Adv Sci. 2020;7(15):2000704

49. Hurley JC. Candida-acinetobacter-pseudomonas interaction modelled within 286 ICU infection prevention studies. J Fungi. 2020;6(4):252.

50. Sur D, Ochiai RL, Bhattacharya SK, et al. A cluster-randomized effectiveness trial of Vi typhoid vaccine in India. N Engl J Med. 2009;361:335-44.

\section{Publisher's Note}

Springer Nature remains neutral with regard to jurisdictional claims in published maps and institutional affiliations.
Ready to submit your research? Choose BMC and benefit from:

- fast, convenient online submission

- thorough peer review by experienced researchers in your field

- rapid publication on acceptance

- support for research data, including large and complex data types

- gold Open Access which fosters wider collaboration and increased citations

- maximum visibility for your research: over $100 \mathrm{M}$ website views per year

At BMC, research is always in progress.

Learn more biomedcentral.com/submissions 